\title{
Damage Evaluation of Carburizing Gear for Remanufacturing*
}

\author{
Tomohisa Kanazawa ${ }^{1}$, Masao Hahakawa ${ }^{2}$, Mitsuhiro Yoshimoto ${ }^{1}$, Yuuki Tahara ${ }^{3}$, Norihito Hata ${ }^{1}$, \\ Susumu Meguro ${ }^{2}$, Takanobu Hiroto ${ }^{2}$, Yoshitaka Matsushita ${ }^{2}$ and Michio Sugawara ${ }^{1}$ \\ ${ }^{1}$ Remanufacturing Promotion Division, Parts Department, Hitachi Construction Machinery Co., Ltd, Tsuchiura 300-0013, Japan \\ ${ }^{2}$ National Institute for Materials Science (NIMS), Tsukuba 305-0047, Japan \\ ${ }^{3}$ Production Engineering Division, Production \& Procurement Group, Hitachi Construction Machinery Co., Ltd, Tsuchiura 300-0013, Japan
}

To investigate the microstructure and damage of friction-fatigued carburized martensitic steels for the reliability of remanufacturing parts, the retained austenite $(\gamma)$ phase and residual stress were characterized by X-ray diffraction (XRD) and scanning electron microscopy (SEM). We evaluated their changes before and after roller pitching tests, and before and after the operation of the gear parts.

In the roller pitching tests, the retained $\gamma$ phase decreased with increasing load and number of cycles, presumably due to martensitic transformation caused by the cyclic load. The residual stress ratio (after/before the test) was significantly lower at high loads than that before testing, which was ascribed to the appearance of surface microcracks and the resultant release of internal stress. From SEM observations of the cross-section of the friction surface, we confirmed that the changes in the retained $\gamma$ phase and residual stress ratio reflect the process of formation of multiple microcracks in the $10 \mu \mathrm{m}$ surface layer. The decreases in both the retained $\gamma$ phase ratio and the residual stress ratio would therefore appear to rule out reuse. A decision on the potential for gear reuse can be made by means of non-destructive testing, i.e., investigating the relationship between the retained $\gamma$ phase ratio and the residual stress ratio. [doi:10.2320/matertrans.MT-M2021132]

(Received July 27, 2021; Accepted August 19, 2021; Published October 4, 2021)

Keywords: carburizing, gear, remanufacturing, residual stress, retained austenite, $x$-ray diffraction, cos $\alpha$ method

\section{Introduction}

The reuse of remanufactured parts in the repair and maintenance of machines is a common practice worldwide. 'Remanufactured part' is used as a generic term for such parts. For example, in the aircraft industry, remanufacturing expertise is used by manufacturers as well as by end-users, such as airline companies, for regular maintenance. ${ }^{1)}$ Although the unit price of automotive parts is lower than that of aircraft parts, the automotive parts industry also has a high demand for remanufactured parts due to the large numbers of vehicles sold. ${ }^{2,3)}$

Mining machines are required to run for about 20 hours per day, 365 days per year (equivalent to about 5,000 to 6,000 hours per year) for about 10 years, but they must be taken out of service for regular overhauls. ${ }^{4)}$ Long out-of-service time is a factor that significantly affects urban infrastructure development and resource mining operations. The crucial need for construction machinery manufacturers to bring machines back into service as quickly as possible creates a strong demand for remanufactured parts in the field of construction and mining machinery. ${ }^{5,6)}$ During maintenance, for example of machines by established repair service providers, components removed from a machine in operation, such as hydraulic equipment, are overhauled at a repair facility. The machine cannot be used during this period, resulting in a long out-of-service time. It is also generally difficult to achieve the manufacturer's recommended quality using the repair equipment available at the repair facility. Maintenance with remanufactured parts, however, has the following advantages. It allows for

(1) Provision of equipment of quality comparable to that of new equipment

*This Paper was Originally Published in Japanese in J. Japan Inst. Met. Mater. 85 (2021) 198-206.
(2) Provision of equipment at $60-70 \%$ the price of new equipment

(3) A shorter out-of-service time because the equipment is replaced onsite.

The use of remanufactured parts therefore contributes significantly to reducing the out-of-service time and maintenance cost of machines. The reuse of parts also reduces the consumption of mineral resources and is a major contributor to building a circular-based economy. ${ }^{7)}$

The major remanufactured parts used by construction machinery manufacturers include hydraulic cylinders, hydraulic pumps and reducers. Gear parts (particularly those for mining machines) commonly used in reducers are expensive and are scrapped at high rates. For this reason, it is necessary that in the remanufacturing process, gear parts be removed from hydraulic components that have been used for a certain period of time, assessed for integrity (= reusability) and then reused where possible. In the current remanufacturing process, a worker visually inspects only the gear parts that have been subjected to relatively low loads for defects such as gear surface pitting, takes dimensional measurements, and determines whether or not reuse is possible. Table 1 shows the reasons for scrapping gears and the scrap rate. Typical forms of damage are gear surface pitting ${ }^{8,9)}$ and wear. About $30 \%$ of gears without pitting are scrapped. Gear parts used under high loads that exert stresses close to the yield strength of the material are scrapped even if no surface damage is seen by visual inspection. To be able to reuse these parts, it is necessary to establish a science-based damage assessment method based on non-destructive testing (NDT).

When developing an NDT assessment method, it is important to identify factors that affect the condition and service life of gears under operating conditions. External force and degradation caused by heat and corrosion predominantly affect the service life of typical mechanical structures. ${ }^{10)}$ Bearings and gear parts in hydraulic equipment 
Table 1 Scrap rate of gear products.

\begin{tabular}{llll}
\hline Cause & No damage & Pitching & Worn out \\
\hline Sample & & \\
\hline Scrap rate & $30 \%$ & $20 \%$ & \\
\hline
\end{tabular}

and reducers are used in a closed environment and therefore are less affected by thermal degradation and corrosion. A change in mechanical properties and microstructures will be visible when an external load is applied. X-ray diffraction (XRD), which is capable of penetrating material and is sensitive to changes in crystal structure, is effective in identifying cause-and-effect relationships between mechanical properties and changes in microstructure. The following reports on the XRD technique for assessing materials have been published. Nomura et al. $(2011)^{11)}$ conducted a test that combined XRD and eddy current testing and reported that the retained austenite $(\gamma)$ phase in a bearing decreases with increasing fatigue damage. Wang et al. (2013) ${ }^{12)}$ developed a non-destructive technique for assessing metal welds in nuclear reactor components by measuring residual stress using XRD. Kamura et al. $(2018)^{13)}$ proposed a formula for estimating the remaining service life from the correlation between the number of loading cycles and the residual stress in a bearing. In addition, Yoshizaki (2019) ${ }^{14)}$ found that the half width at half maximum (FWHM) of XRD peaks tends to decrease with increasing number of cycles of rotational loading of a gear. These techniques, however, correlate the mechanical properties and the change in microstructure after an element test under certain conditions; they are therefore difficult to apply directly to the assessment of damage to carburized parts, including gears and bearings collected from machines in current use with an unknown loading history.

In this study, with the aim of assessing damage to carburized gears, we investigated changes in the microstructure and mechanical properties of metals by comparing gears, carburized parts collected from a machine in operation, and element-tested specimens. We analyzed the relationship between these factors and propose a method for assessing damage to carburized gears, including those with an unknown operating history.

\section{Test Method}

\subsection{Specimens}

The specimens used are structural carbon steel for machinery, JIS SCM420 (0.18-0.23\% C, 0.60-0.85\% Mn, $0.15-0.35 \%$ Si, $0.90-1.20 \%$ Cr, $0.15-0.30 \%$ Mo, $\mathrm{P} \leq$ $0.030 \%, \mathrm{Si} \leq 0.030 \%, \mathrm{Ni} \leq 0.25 \%, \mathrm{Cu} \leq 0.30 \%$ : $\operatorname{mass} \%)$.
The specimens were normalized in accordance with JIS B6911 and then carburized under the same heat treatment conditions. ${ }^{15)}$ The Vickers hardness was $H \mathrm{~V} 350-400$ inside the specimen and $H \mathrm{~V} 700-800$ in the carburized layer. Figure 1(a) shows the shape of the specimens used in the element test that simulates how gear teeth engage with each other. Figure 1(b) shows the shapes of specimens cut out of the gears (with an outer diameter of $150 \mathrm{~mm}$ ) collected from a machine in operation. No evident cracks were found in the surface of any of the gears collected from machines in operation.

\subsection{Element test and observation of surface damage}

A roller-pitting test was conducted as an element test. As shown in Fig. 1(a), the specimen consists of a drive roller and a brake roller. During testing, a load is applied to the brake roller, exerting bearing pressure on the contact surface. The drive roller and the brake roller are linked to the drive motor and the brake motor via the shaft, respectively. A slip can be caused on the sliding surface of the rollers by creating a difference in rotational speed between the motors. The specimen to be evaluated is the one on the brake roller. Table 2 shows the loading conditions during testing. The surface condition of the specimens after testing was observed using a stereo microscope.

\subsection{Observation of microstructure}

Observations were made of the microstructure of crosssections of the carburized layer of the gear specimens before and after roller-pitting testing, and before and after operation. After mirror-surface buffing to achieve a diamond particle size of $1 \mu \mathrm{m}$, electropolishing was performed to identify the tempered martensite phase and the retained $\gamma$ phase. For electropolishing, a solution of 8 vol\% perchloric acid, 10 vol $\%$ butoxyethanol, 70 vol\% ethanol, and $12 \mathrm{vol} \%$ distilled water (liquid temperature of $0^{\circ} \mathrm{C}$ ) was used and a voltage of $50 \mathrm{~V}$ was applied for 8 seconds. ${ }^{16)}$ A field emission scanning electron microscope (FE-SEM) was used to observe the microstructures.

\subsection{X-ray diffraction (XRD)}

First, for characterization of the specimens, the retained $\gamma$ phase ratio in gears before and after operation was determined using a $\theta-2 \theta$ x-ray diffractometer (Rigaku 
(a) Roller-pitching test

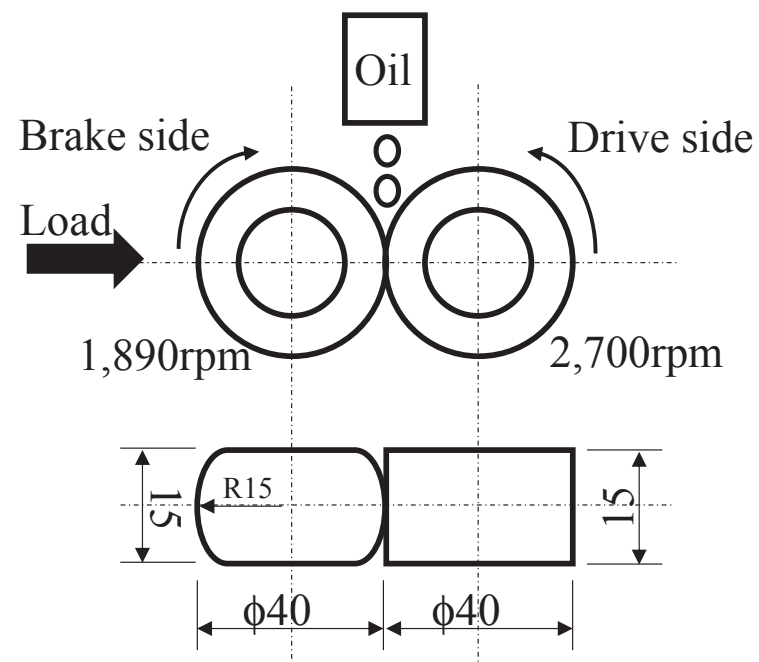

(b) Tooth surface of gear

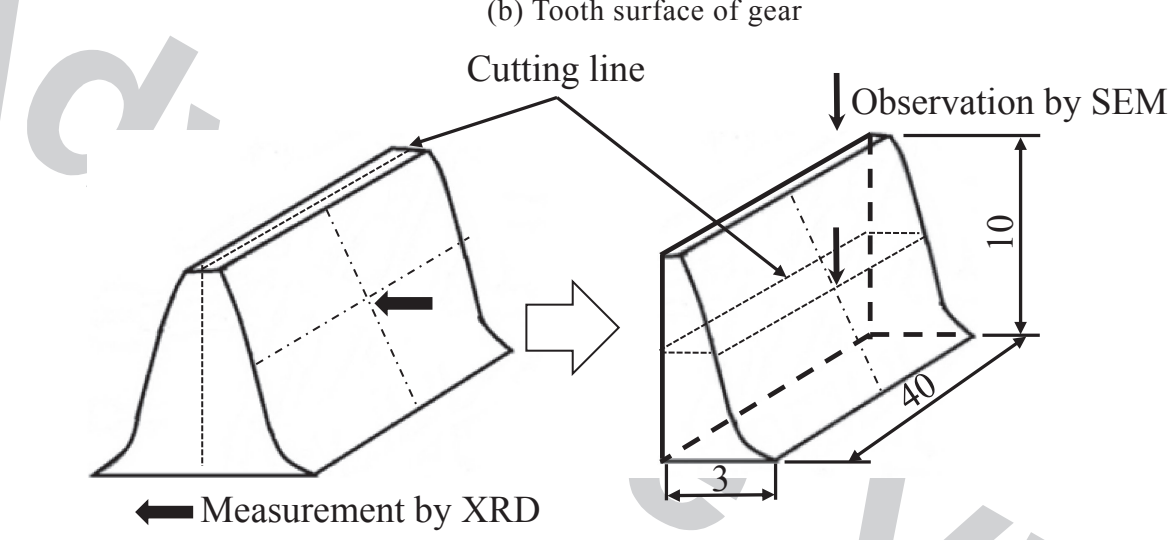

Fig. 1 Schematics of (a) roller-pitching test and (b) tooth surface of gear.

Table 2 Testing conditions of roller-pitching.

\begin{tabular}{ccccccc}
\hline No. & $\begin{array}{c}\text { Load, } \\
P / \mathrm{kN}\end{array}$ & $\begin{array}{c}\text { Surface press, } S \mathrm{P} \\
/ \mathrm{GPa}\end{array}$ & $\begin{array}{c}\text { Slip rate, } \mathrm{Sr} \\
(\%)\end{array}$ & Used oil & $\begin{array}{c}\text { Flow rate, } \\
F \mathrm{r} /(\mathrm{ml} / \mathrm{min})\end{array}$ & $\begin{array}{c}\text { Temp., } \\
T /{ }^{\circ} \mathrm{C}\end{array}$ \\
\hline 1 & 1 & 2.0 & 30 & GL490 & $300-450$ & $80 \pm 5$ \\
\hline 2 & 6 & 3.7 & & & & \\
\hline
\end{tabular}

Corporation, Smart Lab, $45 \mathrm{kV}, 200 \mathrm{~mA}, \mathrm{Cu} \mathrm{K} \alpha_{1}$ ray $(\lambda=$ $1.5406 \AA)$ ).

Second, $\cos \alpha$ was used, which allows for in situ measurement and measurement of gear shape, since the diffractometer is portable and has a high degree of freedom in measuring the shape of specimens before and after rollerpitting testing and gears before and after operation. ${ }^{17-19)}$ The retained $\gamma$ phase ratio and the residual stress were measured using an X-ray diffractometer (Pulstec Industrial Co., Ltd. $\mu \mathrm{X}-360 \mathrm{~s}, \quad 30 \mathrm{kV}, \quad 1.5 \mathrm{~mA}, \quad \mathrm{Cr} \mathrm{K} \alpha$ ray $(\lambda=2.2910 \AA))$. Measurements were made before and after testing all specimens at the same location. The $\cos \alpha$ method allows a value closer to the average residual stress to be obtained using an imaging plate as the detector and diffraction lines around the Debye-Scherrer ring.

The principle of measuring the residual stress and the retained $\gamma$ phase ratio is described in detail below. Both the $\theta-2 \theta$ and $\cos \alpha$ methods are based on Bragg's diffraction conditions and the theory of elasticity, and thus are based on the same principles. For example, in the simple unit cell shown in Fig. 2(a), under Bragg's diffraction conditions, $\mathrm{X}$-rays that are incident on the measurement surface and diffracted are given by eq. (1) below:

$$
2 d \sin \theta=n \lambda
$$

where $d$ : lattice spacing, $\theta$ : Bragg angle, $\lambda$ : X-ray wavelength, and $n$ : diffraction order. For characteristic X-rays with a given wavelength $\lambda$, the following equation is obtained by differentiating eq. (1):

$$
\varepsilon=\frac{d-d_{0}}{d}=\left(\theta_{0}-\theta\right) \cot \theta_{0}
$$

where $\varepsilon$ : strain, $d_{0}$ : value of $d$ with no strain, $\theta_{0}$ : value of $\theta$ with no strain. From the above, the strain $\left(\varepsilon_{\alpha}\right)$ obtained by 

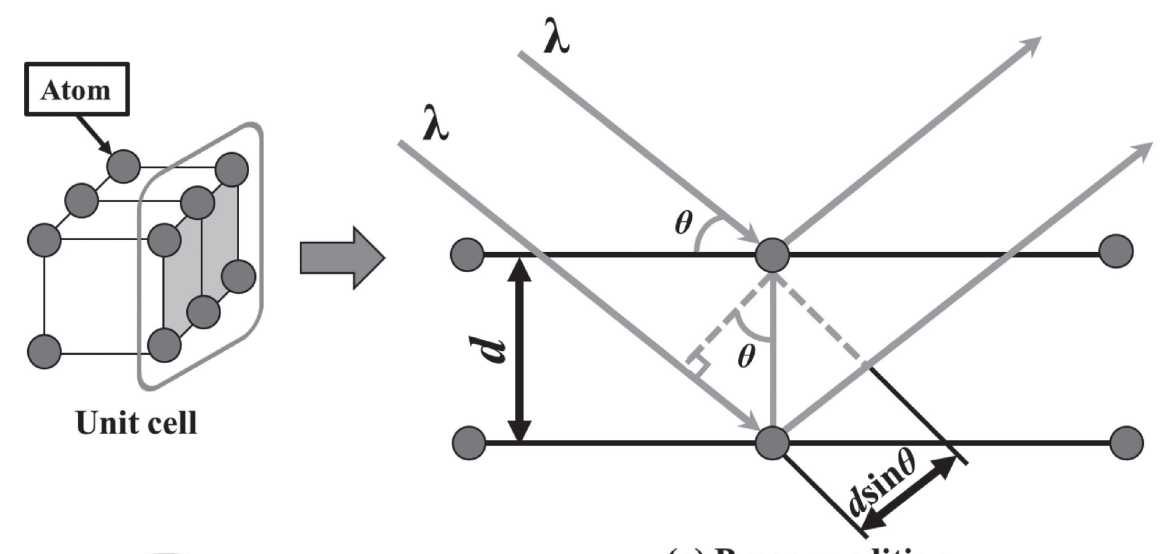

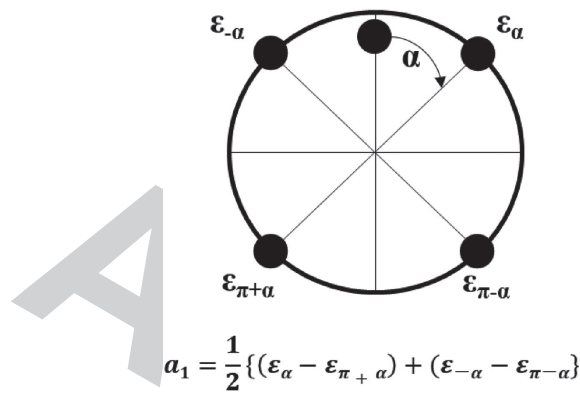

(b) X-ray strain (a) Bragg condition

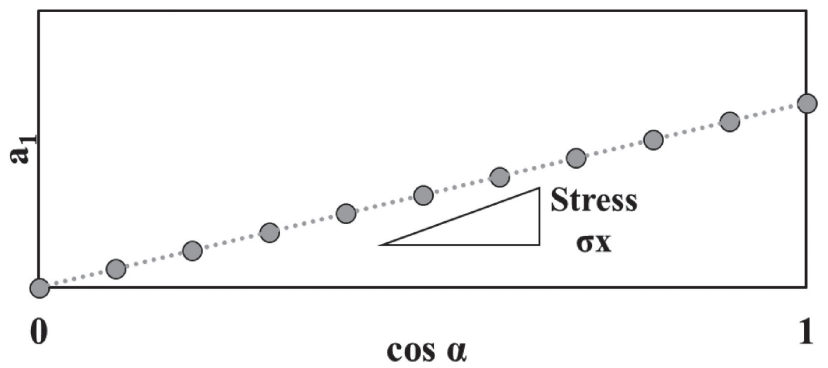

(c) $\cos \alpha$ diagram

Fig. 2 Principles of the XRD measurement method. (a) Basic principles of $2 \theta-\theta$ method and cos $\alpha$ method under Bragg conditions. (b), (c) X-ray strain and $\cos \alpha$ diagram using the $\cos \alpha$ method.

X-ray diffraction at the lattice spacing in Fig. 2(b) can be obtained. The residual stress $\sigma_{\mathrm{x}}$ is obtained based on Hooke's law by calculating the average strain $\varepsilon_{\alpha}$ obtained above. The relationships in eqs. (3) to (5) are assumed to hold.

$$
\begin{aligned}
\sigma_{\mathrm{x}} & =K \mathrm{c} \times M \mathrm{c} \\
K c & =\frac{E}{1+v} \frac{1}{\sin 2 \eta} \frac{1}{\sin 2 \psi_{0}} \\
M c & =\left(\frac{\partial a_{1}}{\partial \cos \alpha}\right)
\end{aligned}
$$

where $K \mathrm{c}$ : order of stress in the $\cos \alpha$ method, E: Young's modulus, $v$ : Poisson's ratio, $\psi_{0}$ : incident angle of X-rays from the normal direction of the specimen, $\eta$ : angle between the incident X-ray and the diffracted X-ray. From the above relationships, the stress $\sigma_{\mathrm{x}}$ can be obtained by calculating the inclination $M c$ of a line with $\mathrm{a}_{1}$ as the vertical axis and $\cos \alpha$ as the horizontal axis, as shown in Fig. 2(c). ${ }^{19,20)}$

The diffracting surface is determined by the angle of each peak after X-ray diffraction, and the retained $\gamma$ phase ratio can be evaluated by calculating the ratio of the integrated peak intensities.

\section{Test Results and Discussion}

\subsection{Change in phase ratio associated with the difference in XRD methods}

The results obtained by these two methods (the $2 \theta-\theta$ method and the $\cos \alpha$ method) are described below. Figures 3(a) and 3(b) show X-ray diffraction peaks before and after operation that were measured using the two methods. Gear parts before and after operation were measured. The $2 \theta-\theta$ method in Fig. 3(a) can detect multiple peaks in the angle range of $30^{\circ}$ on the lower angle side and $100^{\circ}$ on the higher angle side, and it can identify the phase. The $\cos \alpha$ method in Fig. 3(b) can identify the phase with two peaks at $129^{\circ}$ (retained austenite phase) and at $156^{\circ}$ on the higher angle side (martensite phase).

The diffraction peaks show that for the two methods shown in Figs. 3(a) and 3(b), before testing, the intensity of peaks tends to be high for the martensite phase and low for the retained $\gamma$ phase. After testing, this change can be clearly detected, with the intensity of peaks for the retained $\gamma$ phase being lower and that for martensite phase being relatively higher.

The retained $\gamma$ phase ratio can be obtained by calculating the ratio of the integrated intensities. In the $2 \theta-\theta$ method in Fig. 3(a), the retained $\gamma$ phase ratio in the specimens is $24 \%$ before operation and $5 \%$ after operation. In the $\cos \alpha$ method in Fig. 3(b), it is $21 \%$ before operation and $6 \%$ after operation. Thus, no significant difference in measured ratio is found.

\subsection{Change in retained $\gamma$ phase and residual stress}

Since the fraction of the retained $\gamma$ phase and the residual stress before testing (before operation) varied, for damage assessment, we used the values obtained by dividing the retained $\gamma$ phase ratio and the residual stress after testing by those before testing. Figure 4(a) shows the relationship between the retained $\gamma$ ratio (after/before testing) and the number of cycles. The retained $\gamma$ ratio before testing is $13-$ $18 \%$. Measurements were made before and after testing at the same location for all specimens. Therefore, a retained $\gamma$ phase ratio of 1 means that the gear is in new condition. The 


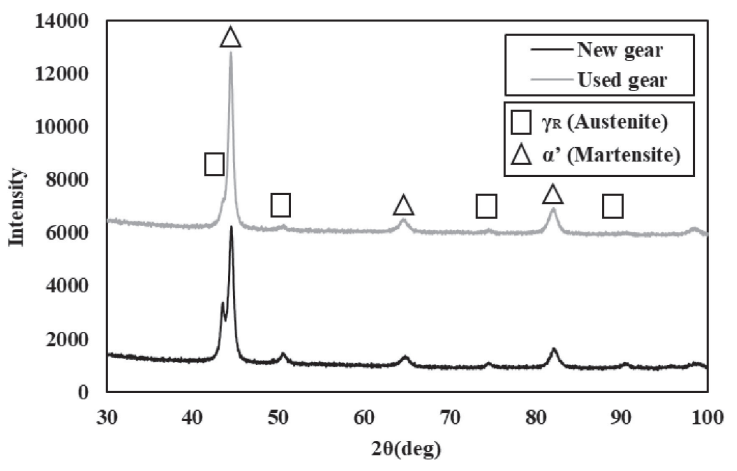

(a) $2 \theta-\theta$ method

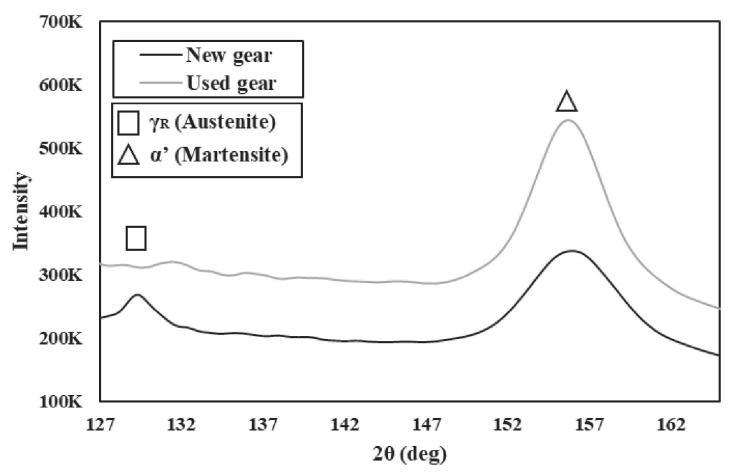

(b) $\cos \alpha$ method

Fig. 3 XRD profiles using (a) $2 \theta-\theta$ method, (b) $\cos \alpha$ method. After operation, both methods tend to show a decrease in retained austenite $\left(\gamma_{\mathrm{R}}\right)$ and an increase in martensite $\left(\alpha^{\prime}\right)$.

(a)

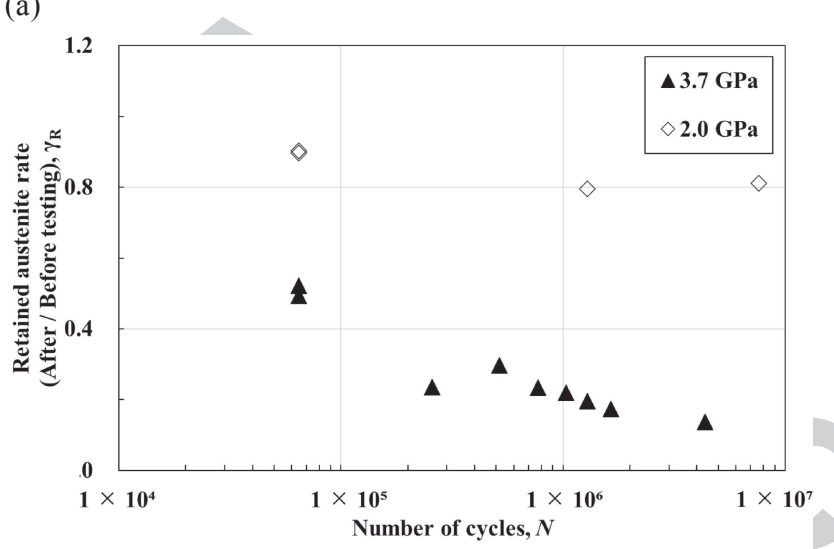

(b)

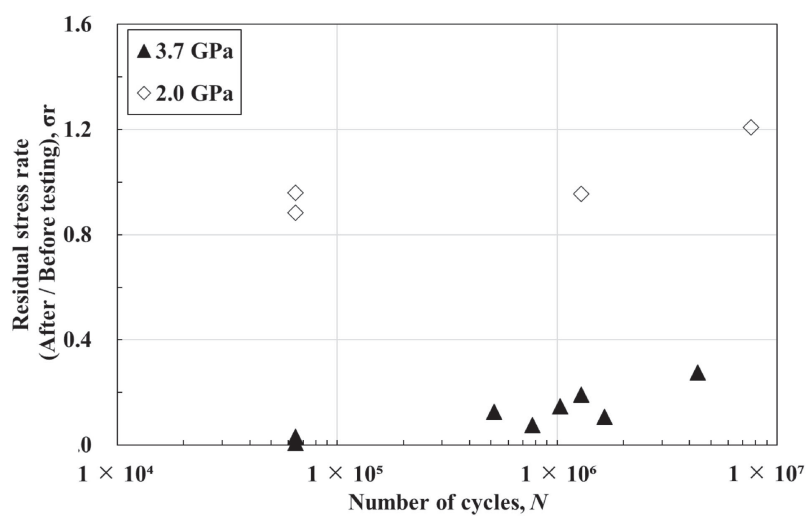

Fig. 4 Relationships between (a) retained austenite rate (after/before testing) and (b) residual stress rate (after/before testing) versus number of cycles. The differences of the retained austenite and residual stress ratios from $2.0 \mathrm{GPa}$ and $3.7 \mathrm{GPa}$ are remarkable.

Figure shows the results for contact pressures of $2.0 \mathrm{GPa}$ and 3.7 $\mathrm{GPa}$. The retained $\gamma$ phase ratio decreases as the number of cycles increases. The decrease is greater for $3.7 \mathrm{GPa}$ than for $2.0 \mathrm{GPa}$. For $3.7 \mathrm{GPa}$, the ratio is 0.5 at $6 \times 10^{4}$ cycles and falls to 0.2 at $1 \times 10^{6}$ cycles. For $2.0 \mathrm{GPa}$, the ratio is 0.9 at $6 \times 10^{4}$ cycles and 0.8 at $1 \times 10^{6}$ cycles. Although the ratio of change as a function of number of cycles is low, the retained $\gamma$ phase ratio decreases slightly.

Figure 4(b) shows the relationship between the residual stress ratio (after/before testing) and number of cycles. The compressive residual stress is $620-750 \mathrm{MPa}$ before testing. It was measured at the same location as for the retained $\gamma$ phase in Fig. 4(a). A residual stress ratio of 1 means that the gear is new. For $2.0 \mathrm{GPa}$, the residual stress ratio is 0.9 at $6 \times 10^{4}$ cycles in the low cycle fatigue regime and gradually increases to 1.2 at $8 \times 10^{6}$ cycles in the high cycle fatigue regime. For $3.7 \mathrm{GPa}$, the residual stress ratio decreases to nearly 0 at $6 \times 10^{4}$ cycles and then gradually increases to about 0.3 at $4 \times 10^{6}$ cycles.

No comparison was made of the condition of gears at the same location before and after operation. Compared to gears before operation (retained $\gamma: 20 \%$, compressive residual stress: $600 \mathrm{MPa}$ ), the retained $\gamma$ phase ratio for the gears before operation decreased to $8.4-13 \%$. The ratio (for the gears after/before operation) is in the range of $0.4-0.7$. The compressive residual stress increases to $730-1,060 \mathrm{MPa}$, and the ratio (for the gears after/before operation) is in the range of $1.2-1.8$.

\subsection{Change in surface condition associated with friction fatigue}

Figure 5 shows the surface condition of the specimen before and after roller pitting testing. As with the gears before testing in Fig. 5(a), no clear cracks were found at a contact pressure of $2.0 \mathrm{GPa}\left(6.4 \times 10^{4}, 1.3 \times 10^{6}\right.$ cycles $)$ in Figs. 5(b) and 5(c). For $3.7 \mathrm{GPa}\left(2.6 \times 10^{5}\right.$ cycles $)$ in Fig. 5(d), clear cracks are found on the rolling contact surface. Pits are found, as shown in Fig. 5(e). The surfaces of the gears before operation in Fig. 5(f) look similar to those of gears before testing. Although scratch marks are present on the surfaces of the gear after operation in Fig. 5(g), no clear cracks or pits are present. Therefore, the gears after operation are determined by visual inspection to be reusable. The surface condition indicates that they are in a condition similar to that of the specimens at $2.0 \mathrm{GPa}$. Clear cracks and pits are present in all specimens at $3.7 \mathrm{GPa}$, indicating that the damage had progressed faster under high stress than in the gears after operation.

\subsection{Quantitative assessment of the retained $\gamma$ phase by observation of the microstructure of cross-sections of the carburized layer}

The retained $\gamma$ phase is thought to contribute to enhancing the microstructure of tempered martensite after carburizing 
(b) 2.0 GPa $\left(6.4 \times 10^{4}\right.$ cycles $)$

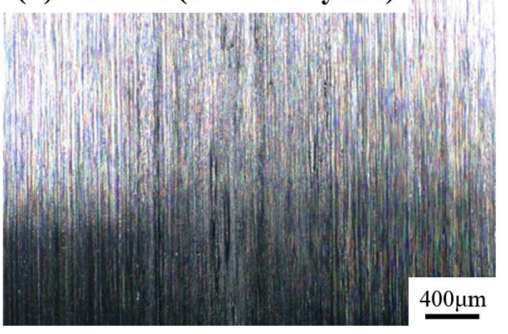

(a) Before operating

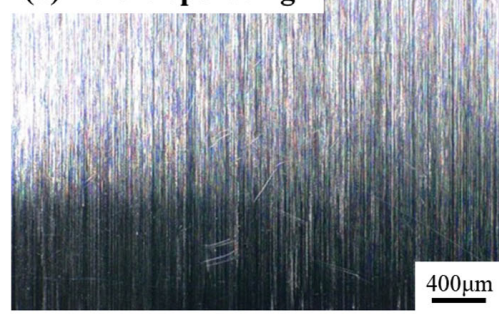

(d) $3.7 \mathrm{GPa}\left(2.6 \times 10^{5}\right.$ cycles $)$

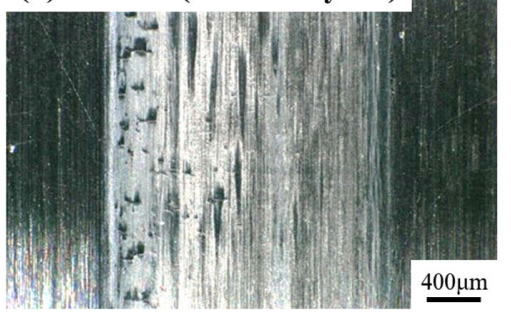

(c) $2.0 \mathrm{GPa}\left(1.3 \times 10^{6}\right.$ cycles $)$

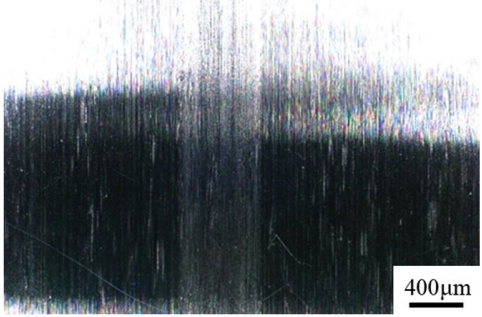

(e) $3.7 \mathrm{GPa}\left(1.3 \times 10^{6}\right.$ cycles $)$

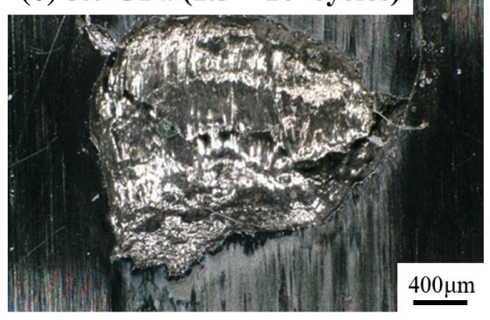

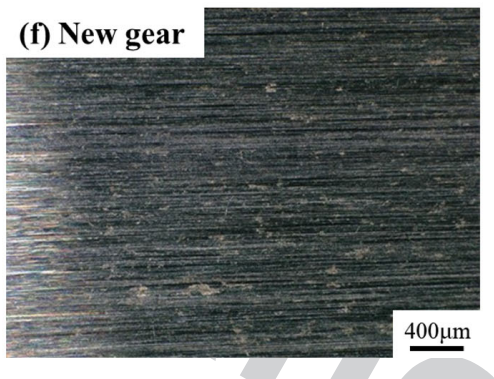

(g) Used gear

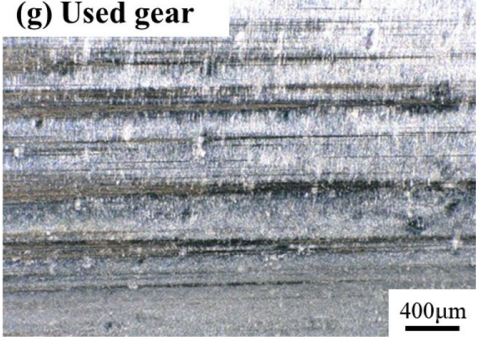

Fig. 5 Appearance of the surfaces for testing $(2.0 \mathrm{GPa}$ and $3.7 \mathrm{GPa})$ and gears. Cracks and pitching appear in the low-cycles region at $3.7 \mathrm{GPa}$, but not in the high-cycles region at $2.0 \mathrm{GPa}$. The appearance of the used gear is similar to that at $2.0 \mathrm{GPa}$.

(a) Before testing (=New gear)

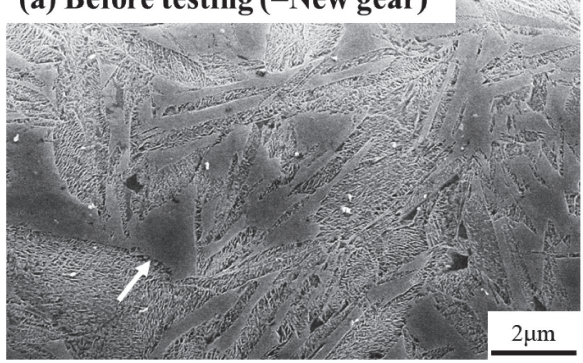

(b) Used gear

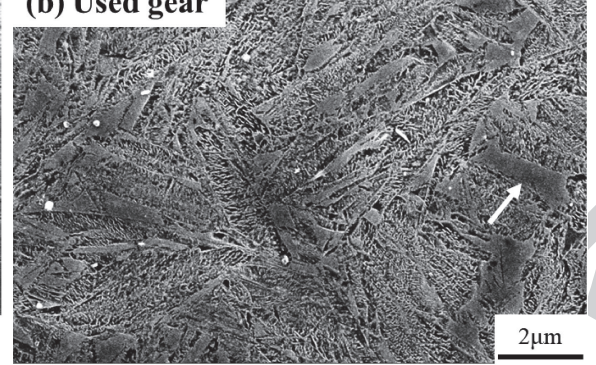

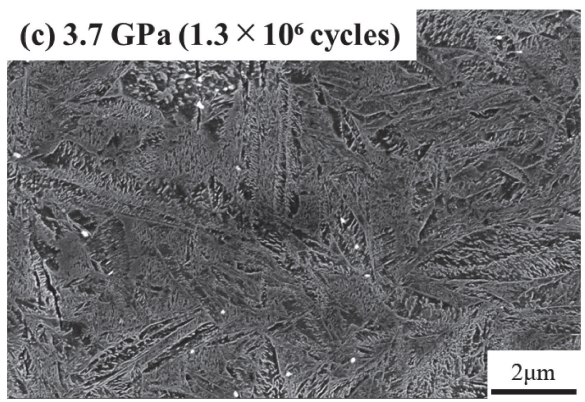

Fig. 6 SEM images of the microstructures of tempered martensite and retained austenite following the carburizing treatment. Arrows in (a) and (b) show typical retained austenite phase, which has almost disappeared in (c).

treatment. $^{21)}$ Figure 6 shows typical SEM images of crosssections of the carburized layer. Figure 6(a) shows an SEM image of a gear before testing. Plate-like martensite blocks are formed in the tempered martensite phase, and carbide particles are present on the boundary of and within the block. The retained $\gamma$ phase (indicated by the white arrow) is shown as a region of single contrast, with no precipitants present on the boundary of or within the region. Retained $\gamma$ grains with a width of up to $0.5 \mu \mathrm{m}$ (grain area of about $0.5 \mu \mathrm{m}^{2}$ ) are the commonest. Retained $\gamma$ grains with a width of more than $2 \mu \mathrm{m}$ (grain area of up to $25 \mu^{2}$ ) are less common. Figure 6(b) shows a cross section of the carburized layer of 


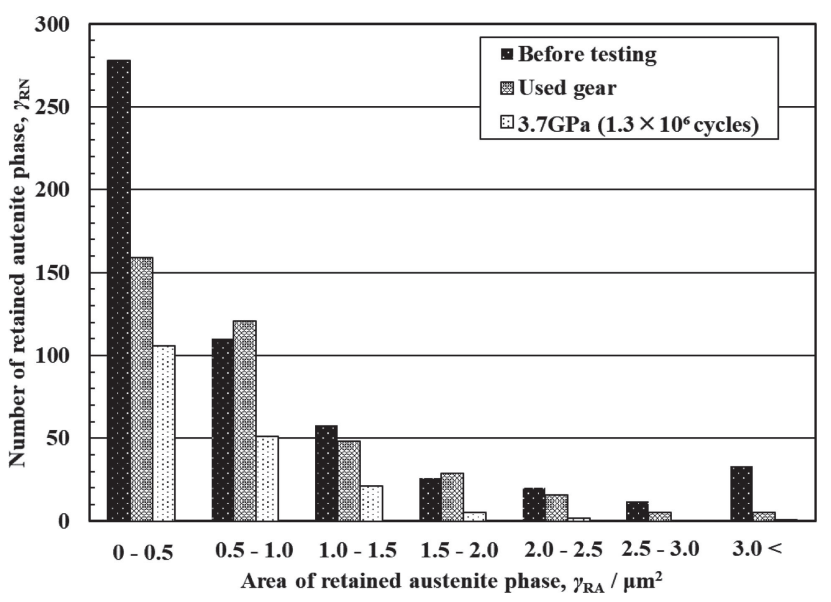

Fig. 7 Distribution of retained austenite size before testing, used gear and $3.7 \mathrm{GPa}$ specimen $\left(1.3 \times 10^{6}\right.$ cycles $)$. In used gears, coarse retained austenite phase more than $2 \mu \mathrm{m}^{2}$ decreased. In $3.7 \mathrm{GPa}$ specimen, the retained austenite almost disappeared.

the gears after operation. Compared to the surface condition in Fig. 6(a), there are almost no coarse austenite grains with a width exceeding $2 \mu \mathrm{m}$. It is likely that coarse retained $\gamma$ grains preferentially transformed into martensite. Figure 6(c) shows a cross section of the carburized layer of the gear with pitting at a contact pressure of $3.7 \mathrm{GPa}\left(1.3 \times 10^{6}\right.$ cycles). Unlike the surface condition in Figs. 6(a) and (b), finer retained $\gamma$ grains are not present.

Figure 7 shows a histogram of the grain area of the retained $\gamma$ phase, which reflects the results in Fig. 6. The figure shows the area of each grain of the retained $\gamma$ phase in five fields of view with a width of $20 \mu \mathrm{m}$ at a depth of $15 \mu \mathrm{m}$ from the surface. In the gears before operation, the total number of grains in the five fields of view is 537; the average area of grains is $0.74 \mu \mathrm{m}^{2}$; and the area ratio (the ratio of the total area of the retained $\gamma$ grains to the area of the field of view) is $25 \%$. For the gears after operation, the total number of grains, the average grain area and the area ratio decrease to $383,0.56 \mu \mathrm{m}^{2}$ and $14 \%$, respectively. For gears with progressing surface damage at a contact pressure of $3.7 \mathrm{GPa}$, the total number of grains, the average grain area, and the area ratio are $186,0.59 \mu \mathrm{m}^{2}$ and $5 \%$, respectively. All of these values decrease as the load increases.

\subsection{Investigation of relationships between the retained $\gamma$ phase and the residual stress, and damage mechanisms}

Figure 8 shows the relationship between the residual stress ratio and the retained $\gamma$ phase ratio. The Figure shows the results for the roller-pitted specimens and gears collected after operation. For the gears before testing and the gears before operation, the retained $\gamma$ phase ratio on the horizontal axis and the residual stress ratio on the vertical axis are all 1 . For the gear at $2.0 \mathrm{GPa}$ and the gears after operation, when the load is repeated, the retained $\gamma$ phase ratio decreases and the residual stress ratio increases. When the retained $\gamma$ phase ratio (face-centered cubic: FCC) transforms to the martensite phase (body-centered cubic: BCC) through deformationinduced transformation, volumetric expansion occurs due to the difference in lattice density between FCC and BCC.

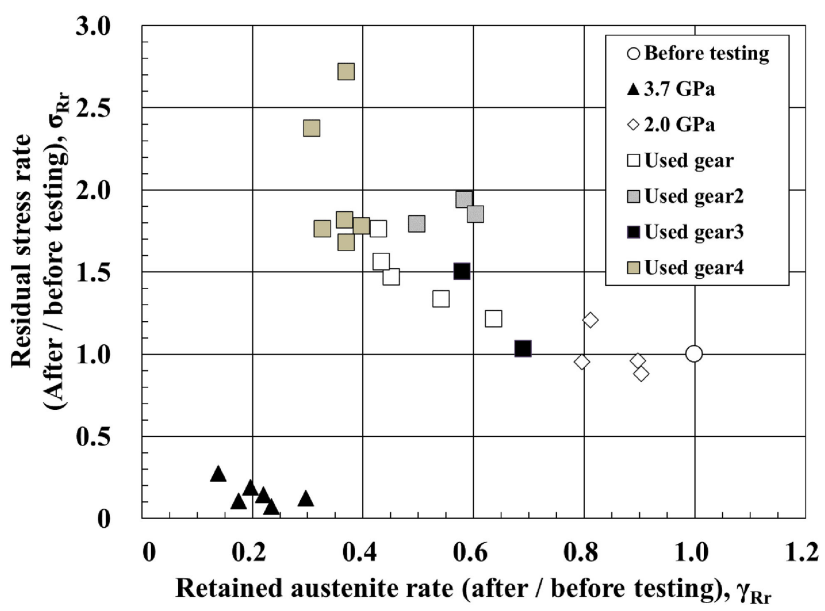

Fig. 8 Residual stress ratio versus retained austenite ratio. As the retained austenite ratio decreased, the residual stress ratio of used gears and 2.0 $\mathrm{GPa}$ without pitching increased, but that of $3.7 \mathrm{GPa}$ with pitching was very low. The internal stress appears to be released by the surface microcracks.

Internal stress $\Delta \sigma$, however, is likely to occur due to the restriction of deformation of the surface layer. When the strain value was estimated based on the difference in lattice density between FCC and BCC, $\Delta \sigma$ was estimated to be $1,150 \mathrm{MPa}=0.55 \times 10^{-2} \times 210 \mathrm{GPa}$ from the product of the strain value and the modulus of elasticity, $210 \mathrm{GPa}^{22)}$ From the general relationship between the hardness and yield stress of low-alloy steel, an internal stress of $1,150 \mathrm{MPa}(=0.55 \times$ $\left.10^{-2} \times 210 \mathrm{GPa}\right)$ indicates that the carburized layer with a Vickers hardness of $H \mathrm{~V} 700$ or more is in the elastic region. If the retained $\gamma$ phase before transformation is treated as a latent defect, the maximum length $a$ is $5 \mu \mathrm{m}(\sqrt{ }$ (maximum area: $\left.\left.25 \mu \mathrm{m}^{2}\right)\right) . \Delta \mathrm{K}$ is calculated to be about $4.6(\mathrm{MPa} \sqrt{ } \mathrm{m})$ from $\Delta \mathrm{K}=\Delta \sigma \sqrt{ } \pi \mathrm{a}$, assuming a small-scale yield criterion as the simplest model. When a load from friction fatigue is added, crack propagation accelerates.

At a contact pressure of $3.7 \mathrm{GPa}$, cracks are formed in the low-cycle fatigue regime, indicating that the restriction of deformation of the surface layer has weakened and the internal stress is relieved, resulting in a significant decrease in residual stress ratio. Through this process, the cracks propagate and grow, resulting in pitting. ${ }^{23)}$ If the formation of coarse-retained $\gamma$ grains can be prevented by controlling the microstructure, cracking and pitting will be prevented.

Figures 9(a) and 9(b) show typical images of cross sections of pits at low and high magnifications. A $2 \mathrm{~mm}-$ wide and $0.5 \mathrm{~mm}$-deep pit is formed. $500 \mu \mathrm{m}$-long cracks are found: one near the surface extending from the side of the pit and one extending from the bottom of the pit in the shear stress direction (at an angle of $45^{\circ}$ to the sliding surface). In the pit, the retained $\gamma$ phase is not present and the residual stress is low. Figures 9(c) and 9(d) show other typical images of cross sections of surface areas away from the pit at low and high magnifications. Multiple micro-cracks are formed in the region at a depth of about $10 \mu \mathrm{m}$ from the surface in the sliding direction. Some cracks run through the surface. XRD measurements in this region show that in the pit, the retained $\gamma$ phase is not present and the residual stress is as low as that in the pit. 
(a)

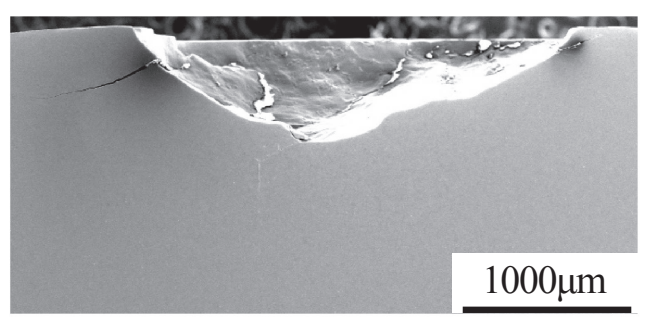

(c)

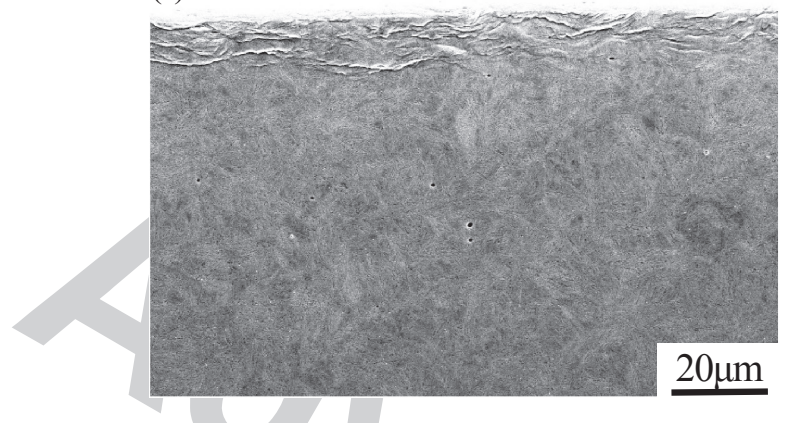

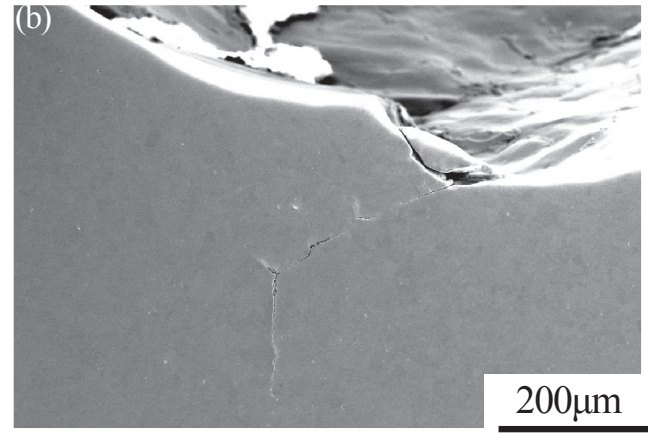

(d)

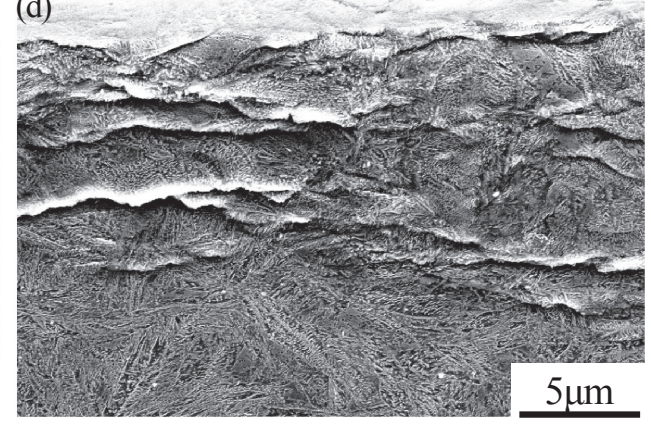

Fig. 9 SEM images of cross-sections showing macro-appearance and long cracks around the pitching fracture surface in (a) and (b) at $3.7 \mathrm{GPa}\left(4.4 \times 10^{6}\right.$ cycles $)$, while cross-sections in $(\mathrm{c})$ and $(\mathrm{d})$ for the microcracks and microstructures in region distant from pitching fractures. The retained austenite phases have already disappeared in (c) and (d).

The rate of change in the retained $\gamma$ phase or residual stress is a parameter that reflects the microscopic-scale damage process up to the point where micro-cracks are visible in the order of $\mu \mathrm{m}$ in the surface layer. It is not a parameter that describes the macroscopic damaging process in which microcracks grow and connect to each other, forming pits. Assessment on the safe side is required to determine whether parts, such as gears and bearings that have been subject to friction fatigue, can be reused. It is more important to describe the microscopic damaging process of the surface layer. The rate of change in the retained $\gamma$ phase and residual stress is a useful parameter in engineering and technology for quantifying microscopic surface damage.

\section{Concept of Damage Assessment Criteria and Issues to be Addressed}

We attempted to develop damage assessment criteria for gears based on the relationship between the residual stress ratio and the retained $\gamma$ phase ratio, as shown in Fig. 8. Figure 10 shows a typical example of the measurement process using the $\cos \alpha$ method. The $\cos \alpha$ method is 10 times faster in making measurements of parts of complex shapes, such as gears, than conventional methods, and the measuring equipment size is $1 / 10$ of that of conventional equipment, making it possible to make measurements highly efficiently.

In gears after operation, the retained $\gamma$ phase ratio tends to be lower and the residual stress ratio tends to be higher. Visual assessment, however, shows no cracks or pits. Observation of the cross section of the surface layer shows that no micro-cracks are present. Conventionally, the reusability of a gear is determined based only on visual

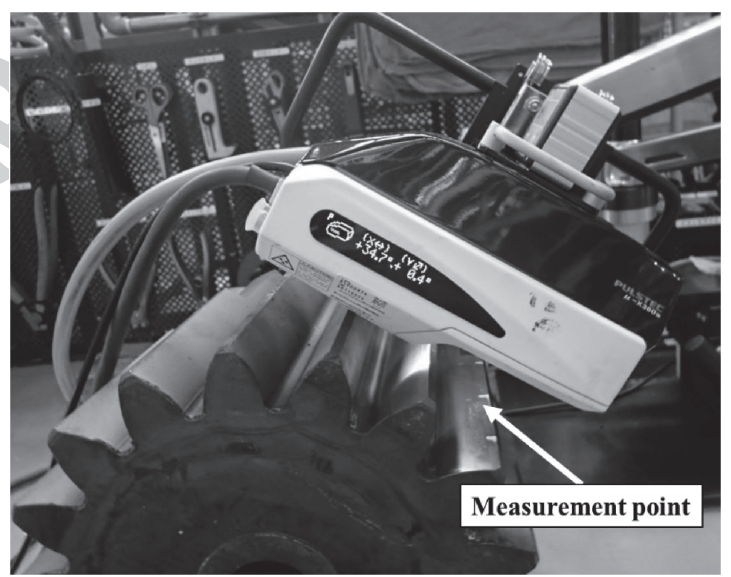

Fig. 10 Typical example of measurements of the gear parts using $\mu-X 360$ s ( $\cos \alpha$ method).

assessment, but it can also be assessed based on the value of the retained $\gamma$ phase ratio and the residual stress ratio.

At a contact pressure of $3.7 \mathrm{GPa}$, the retained $\gamma$ phase ratio and the residual stress ratio are significantly low over the entire area of the sliding surface layer, except for the pits. These results reflect the fact that, as shown by the cross sections in Figs. 9(c) and 9(d), multiple micro-cracks are locally present at a depth of $10 \mu \mathrm{m}$ from the surface. It can therefore be concluded, based on the values of the retained $\gamma$ phase ratio and the residual stress ratio, that some gears that pass a visual assessment may not in fact be suitable for reuse.

In other words, it is essential, to improve the reliability of damage assessment, to develop a database that combines visual assessments, dimensional measurements, non-destruc- 
tive XRD testing and destructive testing based on crosssectional observation. In practice, though, destructive testing cannot be performed to determine reusability. It is anticipated, based on this proposed database, that regions where the retained $\gamma$ phase ratio and the residual stress ratio have decreased, indicating the formation of micro-cracks in local surface regions, will be used as criteria for determining reusability. From the perspective of remanufacturing, improvement in reuse rates of parts is expected to contribute significantly to economic efficiency and the re-use of resources.

\section{Conclusions}

Regarding gears before and after roller-pitting testing at a contact pressure of 2.0 and $3.7 \mathrm{GPa}$ and before and after operation, we identified a relationship between the change in the size distribution of retained $\gamma$ grains over the cross section of a carburized surface layer, as determined by scanning electron microscopy (SEM), and between the retained $\gamma$ phase and the residual stress, as determined by X-ray diffraction (XRD). We obtained the following conclusions.

(1) In the carburized layer, the size of the retained $\gamma$ grains decreases as the load increases and as the number of cycles increases. This is probably due to deformationinduced martensitic transformation.

(2) Observation of the microstructure of the cross section of the carburized layer showed that coarse retained $\gamma$ grains larger than $2 \mu \mathrm{m}^{2}$ readily disappear due to deformation-induced martensitic transformation and fine grains with a size of $0.5 \mu \mathrm{m}^{2}$ or less are easily retained.

(3) At a contact pressure of $2.0 \mathrm{GPa}$, the residual stress ratio was the same as or a little higher than before testing. At a contact pressure of $3.7 \mathrm{GPa}$, it was significantly lower than before testing. The possible reason for this is that the internal stress was relieved by cracking.

(4) As with the results of the roller-pitting test at $2.0 \mathrm{GPa}$, the retained $\gamma$ ratio was lower and the residual stress ratio was higher in gears after operation that showed no surface damage than in those before operation.
(5) Internal stress is caused by the deformation-induced transformation of the retained $\gamma$ phase. Therefore, if the formation of coarse retained $\gamma$ grains can be prevented by controlling the microstructure, crack propagation and pitting will be prevented.

(6) The rate of change in the retained $\gamma$ phase and residual stress appears to be proportional to microcracking in the surface layer. The rate of change in both the retained $\gamma$ phase and in residual stress can therefore be used as a safe-side criterion for determining reusability.

\section{REFERENCES}

1) T. Ishizuka: J. Jpn. Soc. Mech. Eng. 106 (2003) 166-167.

2) M. Matsumoto, K. Chinen and H. Endo: J. Clean. Prod. 205 (2018) 1029-1041.

3) T. Sakao and E. Sundin: J. Manuf. Sci. Eng. 141 (2019) 021004.

4) T. Takenaka, H. Higashide and T. Abe: J. JCMA 63 (2011) 34-38.

5) J. Shibuya: HITACHI Rev. 101 (2019) 488-491.

6) H. Yayama: J. JCMA 62 (2010) 24-28.

7) T. Kanazawa, M. Yoshimoto, K. Ino and M. Sugawara: Abstract of Eco design 2019 C9-2, (2019) pp. 615-617.

8) S. Matsumoto: JSME 81 (2015) 1-8.

9) M. Yoshizaki: JSME 82 (2016) 1-20.

10) K. Fukuya: AESJ 53 (2011) 577-581.

11) T. Nomura, T. Oohira, N. Mitamura, M. Natori, T. Ueda, I. Uematsu and H. Magami: International Patent WO 2011/074654 (2011) pp. 1-35.

12) Y. Wang, S. Okido, H. Hato, T. Kikuchi and A. Chiba: HITACHI Rev. 95 (2013) 454-455.

13) N. Kamura, T. Fujita and T. Sasaki: JSMS 67 (2018) 694-699.

14) M. Yoshizaki: JSME 85 (2019) 1-16.

15) Japanese Standards Association: JIS B6914 (2002) pp. 1-13.

16) M. Hayakawa, S. Terasaki, T. Hara, K. Tsuzaki and S. Matsuoka: J. Japan Inst. Met. Mater 66 (2002) 745-753.

17) S. Taira, K. Tanaka and T. Yamazaki: J. Jpn. Soc. Mech. Eng. 27 (1978) 251-256.

18) T. Sasaki, Y. Kobayashi, T. Sakakibara, Y. Kobayashi, T. Fujita and S. Takago: Sci. Machine 8 (2017) 639-649.

19) T. Sasaki, R. Mizuno, T. Takago and Y. Mishima: JSNDI 66 (2017) $470-476$.

20) T. Sasaki: JSNDI 69 (2020) 568-574.

21) S. Fujiki: Structural Change and Fatigue Strength of Metal, (Nikkan Kogyo Shimbun Co., Ltd., Tokyo, 2004) pp. 111-113.

22) H. Sudou: Residual Stress and Strain, (Uchida Rokakuho Co., Ltd., Tokyo, 1988) p. 127.

23) N. Yoshida and T. Taki: JSME 74 (2008) 702-709. 